\title{
PU.1-Silenced Dendritic Cells Induce Mixed Chimerism and Alleviate Intestinal Transplant Rejection in Rats via a Th1 to Th2 Shift
}

\author{
Xingwei Xu Xin Gao Xiaofan Zhao Yannian Liao Wu Ji Qiurong Li Jieshou Li
}

Jinling Hospital, Research Institute of General Surgery, School of Medicine, Nanjing University, Nanjing, China

\section{Key Words}

PU.1 • Chimerism • Immune • Intestinal transplantation

\begin{abstract}
Background/Aims: Intestinal transplantation is an effective treatment for end-stage bowel failure; however, graft rejection and the toxicity associated with non-specific immunosuppression are major limitations of this procedure. Studies have shown that mixed chimerism can produce post-transplantation immune tolerance. Here, we demonstrate that in rat intestinal transplantation, PU.1-silenced dendritic cells (DCs) plus bone marrow (BM) cell transfusion results in mixed chimerism, and we investigate the mechanisms responsible for the effects of mixed chimerism rejection. Methods: In a model of intestinal transplantation, male Brown Norway rats were the donors, and female Lewis rats were the recipients that were randomly divided into 4 groups: control, BM, BM-imDCs and BM-PU.1. The dynamic changes in graft morphology, rejection scoring and serum concentrations of Th1/Th2-related cytokines were investigated on postoperative days $0,7,14,21$, and 30. Results: The BM-PU.1 group had better graft health, milder pathologic injuries, and lower rejection grades compared with the other groups. The rates of mixed chimerism were significantly highest in the BM-PU.1 group and correlated with decreases in serum IL-2 and increases in serum IL-10. Conclusion: Transfusion of PU.1-silenced DCS and BM cells induces stable mixed chimerism and has the potential to reduce pathologic injuries via a pro-Th2 shift in the Th1/Th2 balance.
\end{abstract}

(C) 2016 The Author(s)

Published by S. Karger AG, Basel

\section{Introduction}

Intestinal transplantation has become an effective treatment for end-stage intestinal diseases and patients who fail on total parenteral nutrition (TPN) [1, 2]. Over the last decade,

JiWu

KARGER
Jinling Hospital, Research Institute of General Surgery, School of Medicine, Nanjing University, 305 East Zhongshan Road, Nanjing 210002, Jiangsu Province, (China)

Tel. +86 2580860005, Fax +86 2580860005, E-Mail Jiwusky@126.com 


\section{Cellular Physiology Cell Physiol Biochem 2016;38:220-228 and Biochemistry Published online: January 20, 2016 \begin{tabular}{l|l} 
DO 2016 The Author(s). Published by S. Karger AG, Basel \\
www.karger.com/cpb
\end{tabular} \\ Xu et al.: PU.1-Silenced DCs Synergized to Alleviate Rejection}

the curative effects of intestinal transplantation have improved significantly due to surgical advances, effective immunosuppressive regimes, and a decrease in lethal infections. Graft rejection rates for isolated intestinal transplants have decreased from $80 \%$ to $30-40 \%$, and 1 -year patient and graft survival rates have increased to $90 \%$ and $80 \%$, respectively, at some experienced transplant centers [3-5]. Although complex immunosuppressive regimes are still needed to attenuate rejection episodes and lengthen survival times, their long-term use can result in sepsis and infections. Today, developing a more effective immunomodulatory strategy that does not incorporate long-term immunosuppression is the key goal, and such a strategy could even be described as the 'Holy Grail' [6].

The establishment of mixed chimeras, which are characterized by the co-existence of donor and host hematopoietic cells, has been successfully demonstrated in pre-clinical and clinical trials [7]. The recipient receives special cells from the donor and establishes a cell population that mixes donor cells with recipient cells [8]. In recipients of transplanted allografts, the use of donor-derived bone marrow cells induces tolerance and helps to achieve long survival times. However, the routine use of mixed chimeras has been hampered by the need to condition the recipient to accept the donor bone marrow cells [9-11]. Often, myeloablation and depletion of immune cells is necessary to condition the recipient for mismatched bone marrow transplants, which presents risks due to toxic side-effects. Graftversus-host disease (GVHD) is also a significant problem when attempting to establish mixed chimeras after myeloablation [6]. To resolve these problems, we silenced the key regulatory factors involved in DC maturation, which may lead to a stunted capacity to prime the immune response and improved chimera stability. The transcription factor PU.1 is predominantly expressed in DCs and is essential for DC differentiation. Recent studies have provided evidence that the PU.1 gene plays a critical role in DC maturation [12] by serving not only as a transcriptional activator but also as a repressor. For instance, in bone marrow-derived DCs, PU.1 up-regulates the expression of DC-characteristic genes, such as class II transactivator (CIITA), CD80, CD86, and IL-12 p40 [13, 14], while suppressing the expression of Th2 cytokines, including IL-13 and IL-5 [15]. PU.1 regulates its target genes through epigenetic modifications, including histone deacetylation and DNA methylation $[16,17]$. Our previous study using an intestinal allograft model showed that compared with immature DCs, PU.1silenced DCs had better and more stable effects in reducing the inflammatory response [18], and therefore, we aimed to establish stable mixed chimerism in a rat model of heterotopic intestinal transplantation (HIT) using simultaneous transfusion of PU.1-silenced DCs and donor-derived bone marrow cells without irradiation or other cytoreductive conditioning. We observed the formation of mixed chimerism, which was accompanied by beneficial effects on histopathological structural integrity, grades of rejection, recipient survival rates, and the ratio of serum levels of IL-2 and IL-10. The objectives of this study are to present a new conditioning approach and improve understanding of the mechanism by which chimerism attenuates injury in transplantation and prolongs graft survival.

\section{Materials and Methods}

\section{Animals and Experimental Design}

Inbred male Brown Norway (BN) rats and female Lewis rats (250 - 280 g) were obtained from Vital River Laboratory Animal Technology Co. Ltd (Beijing, China). Rats were provided with ad libitum access to standard chow and tap water and housed on a 12-h light/dark cycle in a specific pathogen-free animal facility. All animals received humane care, and the study protocols complied with Nanjing University's guidelines and animal research laws. All experimental procedures were approved by our Institutional Animal Care and Use Committee.

Donor dendritic cell isolation and transfusion

Bone marrow cells of BN rats were used for DC generation according to the methods described by Lutz [19] and our previous study [20]. Briefly, BN rats were sacrificed, and femurs and tibias were obtained 


\section{Cellular Physiology Cell Physiol Biochem 2016;38:220-228 \begin{tabular}{cl|l} 
DOI: 10.1159/000438623 & O 2016 The Author(s). Published by S. Karger AG, Basel \\
and Biochemistry & Published online: January 20,2016 \\
www.karger.com/cpb
\end{tabular} \\ Xu et al.: PU.1-Silenced DCs Synergized to Alleviate Rejection}

by dissection. Bone marrow cells were flushed from the bones using phosphate-buffered saline (PBS). The resulting cell suspensions were centrifuged and treated with red cell lysis buffer to remove red blood cells. A portion of the harvested cells were diluted in $0.85 \%$ saline solution at a final density of $4 \times 10^{6} / \mathrm{ml}$ for use as BM cells. Some of the cells were cultured in six-well plates (density, $4 \times 10^{6} / \mathrm{ml}$ ) in RPMI1640 with $5 \mathrm{ng} / \mathrm{ml}$ of recombinant rat granulocyte macrophage colony-stimulating factor (GM-CSF) and $5 \mathrm{ng} / \mathrm{ml}$ of interleukin (IL)-4 (Peprotech, NJ, United States). Nonadherent granulocytes were removed after $48 \mathrm{~h}$ of culture. The cytokine-enriched medium was refreshed every other day. On day 7, non-adherent and loosely adherent cells were harvested and identified as immature DCs. Trypan blue exclusion testing showed more than $95 \%$ cell viability.

\section{PU.1 silencing}

1) Small interfering RNAs (siRNAs) targeting the PU.1 gene were synthesized by Jima Corporation (Shanghai, China). The sequences of the PU.1-specific siRNAs were as follows: sense, 5'-AGC GAU CAC UAU UGG GAU UTT-3'; antisense, 5'-AAU CCC AAU AGU GAU CGC UTT-3'. The sequences of the negative control siRNAs were as follows: sense, 5' -UUC UCC GAA CGU GUC ACG UTT-3'; anti sense, 5' - ACG UGA CAC GUU CGG AGA ATT-3'. 2) Lipofectamine 2000 (Invitrogen, United States) was used according to the manufacturer's instructions to transiently transfect the siRNAs into imDCs for $24 \mathrm{~h}$. 3) The transfected cells were re-plated and cultured in the presence of $10 \mu \mathrm{g} / \mathrm{ml}$ LPS (Sigma Aldrich, United States) for an additional $48 \mathrm{~h}$, and the harvested cells were designated as PU.1-silenced DCs and negative control-silenced DCs. 4) Real-Time PCR and WB were used to monitor the transfection efficiency of the PU.1 siRNAs.

Flow cytometric and mixed lymphocyte reaction (MLR) analysis of cultured cells

Surface molecule expression and phenotypic analysis of the PU.1-silenced DCs was determined by fluorescence-activated cell sorting using a Calibur flow cytometer equipped with Cell Quest (Becton Dickinson, New Jersey, United States). The following antibodies were purchased from eBioscience Corporation (CA, United States): phycoerythrin (PE)-coupled anti-CD86, PE-coupled anti-CD80 and fluorescein isothiocyanate-coupled anti-MHC $\alpha$ The restricted marker for rat DCs, OC-62 Alexa Fluor, was purchased from BioLegend (CA, United States). For the MLR analysis, T cells $\left(2 \times 10^{5}\right)$ purified from rat splenocytes were used as responder cells and were plated with DCs from the different experimental groups at varying ratios. We used Nylon Fiber Column T (Wako, Japan) according to the manufacturer's instructions to separate T-cells. Cells were cultured for $3 \mathrm{~d}$ and pulsed with $1 \mu \mathrm{Ci}$ of $3 \mathrm{H}$-thymidine (PerkinElmer, Woodbridge, United States) for the final $18 \mathrm{~h}$. The cells were subsequently harvested onto glass fiber filters, and the incorporated radioactivity was quantified using a liquid scintillation counter.

\section{Experimental groups}

The allogeneic segmental heterotopic intestinal transplantation (male BN rats to female Lewis rats, HIT) was performed under pentobarbital anesthesia in a sterile field using the cuff technique. A 15-20-cm segment of ileum was removed from a donor and transplanted into the recipient. After vascular anastomosis, a stoma was generated in the abdominal wall of the distal intestine to observe pathological changes. The study included 4 groups: the control group, the pure HIT administration group $(\mathrm{n}=6)$; the BM group, HIT with transfusion of donor-derived bone marrow cells $\left(2 \times 10^{7}\right.$ cells, day 0$)$ via the portal vein (PV) $(n=6)$; the BM-imDCs group, HIT with transfusion of imDCs $\left(2 \times 10^{7}\right.$ cells, day -2$)$ plus donor-derived bone marrow cells $\left(2 \times 10^{7}\right.$ cells, day 0$)(\mathrm{n}=6)$; the BM-PU.1 group, HIT with transfusion of PU.1-silenced DCs $\left(2 \times 10^{7}\right.$ cells, on day -2$)$ plus donor-derived bone marrow cells $\left(2 \times 10^{7}\right.$ cells, day 0$)(n=6)$. The donor marrow cells helped to induce mixed chimerism (Fig. 1).

\section{Histology}

Graft tissues were immersion-fixed in 10\% buffered formalin, embedded in paraffin, sectioned, and stained with hematoxylin-eosin (HE). Specimens from the stomas were obtained at 0, 7, 14, 21 and 30 days after HIT, and rejection grading was performed to estimate the degree of rejection [21].

\section{Real-time PCR analysis}

Real-time PCR for the sex-determining region of the Y chromosome (SRY) was performed using samples of recipient blood, liver, spleen and intestine obtained on day 30. After genomic DNA extraction, the 


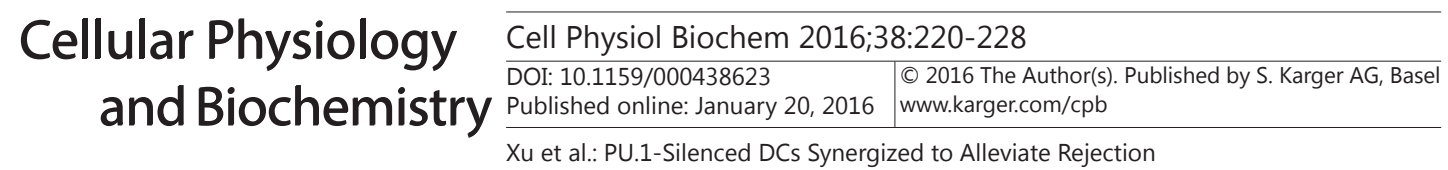

Fig. 1. Flow diagram.

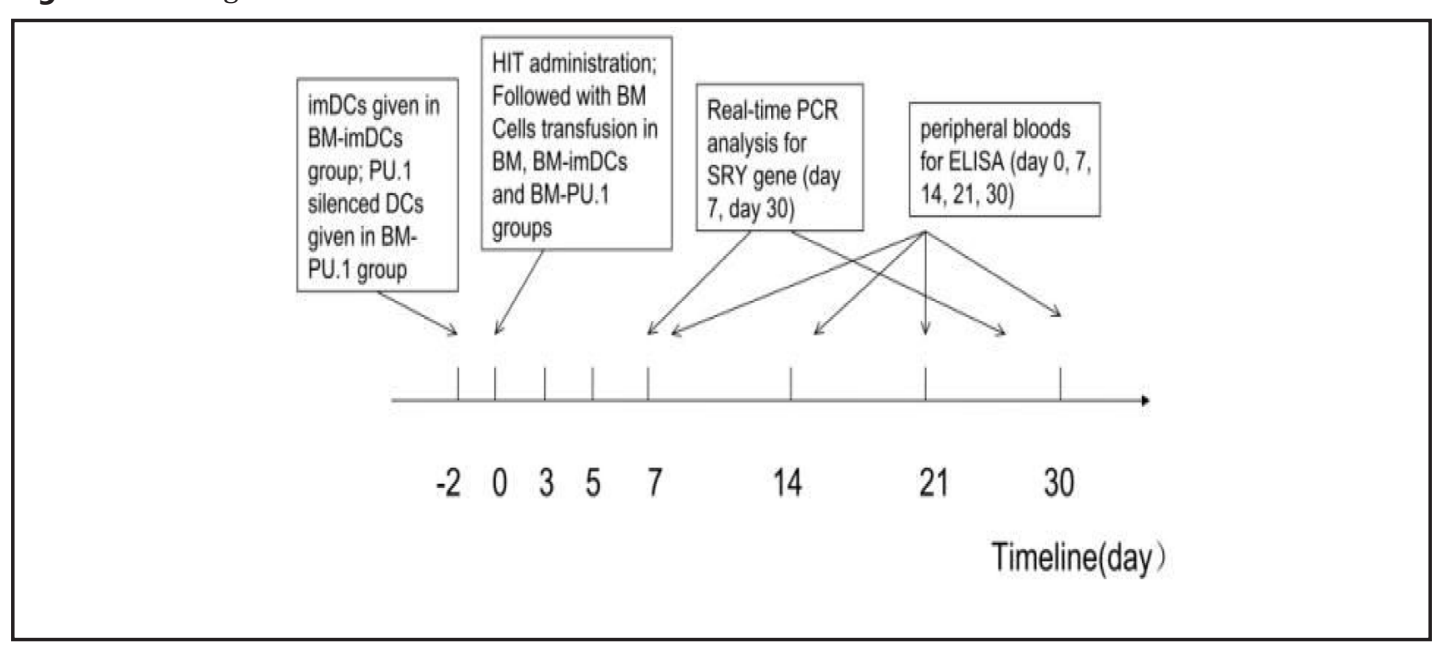

PCR mixture was prepared using SYBR Premix Ex TaqTM (TaKaRa, Dalian, China). The primers used for PCR were 5'-AAG TCA AGC GCC CCA TGA-3' (sense) and 5'-TGA GCC AAC TTG TGC CTC TCT-3' (antisense) [22]. Each $25-\mu \mathrm{L}$ sample was denatured at $95^{\circ} \mathrm{C}$ for 4015 -s cycles, and then subjected to annealing and extension $\left(60^{\circ} \mathrm{C}, 1 \mathrm{~min}, \mathrm{ABI} 7900 \mathrm{HT}\right.$ Fast RealTime PCR System, Applied Biosystems Inc., USA). Genomic DNA from male BN rats was mixed at proportions of $100 \%, 20 \%, 4 \%, 0.8 \%$ and $0.16 \%$ with genomic DNA from female Lewis rats. The mixed DNA samples were used to establish standard curves [23].

Enzyme-labeled immunosorbent assay (ELISA)

Peripheral blood was collected via the tail vein on days 0, 7, 14, 21 and 30 for ELISA. Serum levels of Th1-related cytokines (IL-2) and Th2-related cytokines (IL-10) were assayed in duplicate using a commercial rat IL-2 or IL-10 ELISA Kit (R\&D Systems, Minneapolis, United States) according to the manufacturer's instructions.

Statistical Analysis

All results are expressed as the mean \pm SD. Statistical analyses were performed using one-way analysis of variance (ANOVA) with a post hoc test to ascertain the p-values of differences between groups. All analyses were performed using SPSS 13.0 (SPSS, Chicago, III). $P<0.05$ was considered significant.

\section{Results}

In vivo detection of the immunophenotype and tolerogenic functions of PU.1-silenced DCs

PU.1-silenced DCs were obtained from bone marrow cells cultured in low-dose GM-CSF and IL-4 for 7 days. Similar to the phenotypic characteristics of imDCs $(6.0 \% \pm 1.2 \%, 7.6 \%$ $\pm 1.8 \%$ and $7.4 \% \pm 1.3 \%$ ), PU.1-silenced DCs displayed low expression levels of CD80, CD86 and $\mathrm{MHC} \alpha(27.0 \% \pm 5.6 \%, 23.6 \% \pm 4.8 \%$ and $36.8 \% \pm 6.8 \%$, respectively $)$ compared with mature DCs $(74.0 \% \pm 9.4 \%, 76.5 \% \pm 8.7 \%$ and $87.8 \% \pm 11.3 \%$, respectively) (Fig. 2a). In an MLR, PU.1-silenced DCs inhibited the proliferation of naive Lewis splenocytes as effectively as immature DCs (Fig. 2b). In contrast, when pre-treated with mature DCs, a significantly higher response was observed $(P<0.05)$.

SRY gene real-time PCR assays were used to observe the establishment of mixed chimerism on day 30 (Fig. 3). The relative SRY gene expression in the BM-PU.1 group was higher than that in the BM group $(3.03 \pm 0.16 \%$ vs $1.15 \pm 0.07 \%$ in the blood, $P<0.05 ; 0.86$ $\pm 0.05 \%$ vs $0.21 \pm 0.02 \%$ in the liver, $P<0.05 ; 4.08 \pm 0.12 \%$ vs $1.23 \pm 0.05 \%$ in the spleen, $P<0.05$; and $2.01 \pm 0.27 \%$ vs $0.71 \pm 0.09 \%$ in the intestine, $P<0.05$, respectively). There were no significant differences in relative SRY gene expression between the BM group and the BM-imDCs group. 


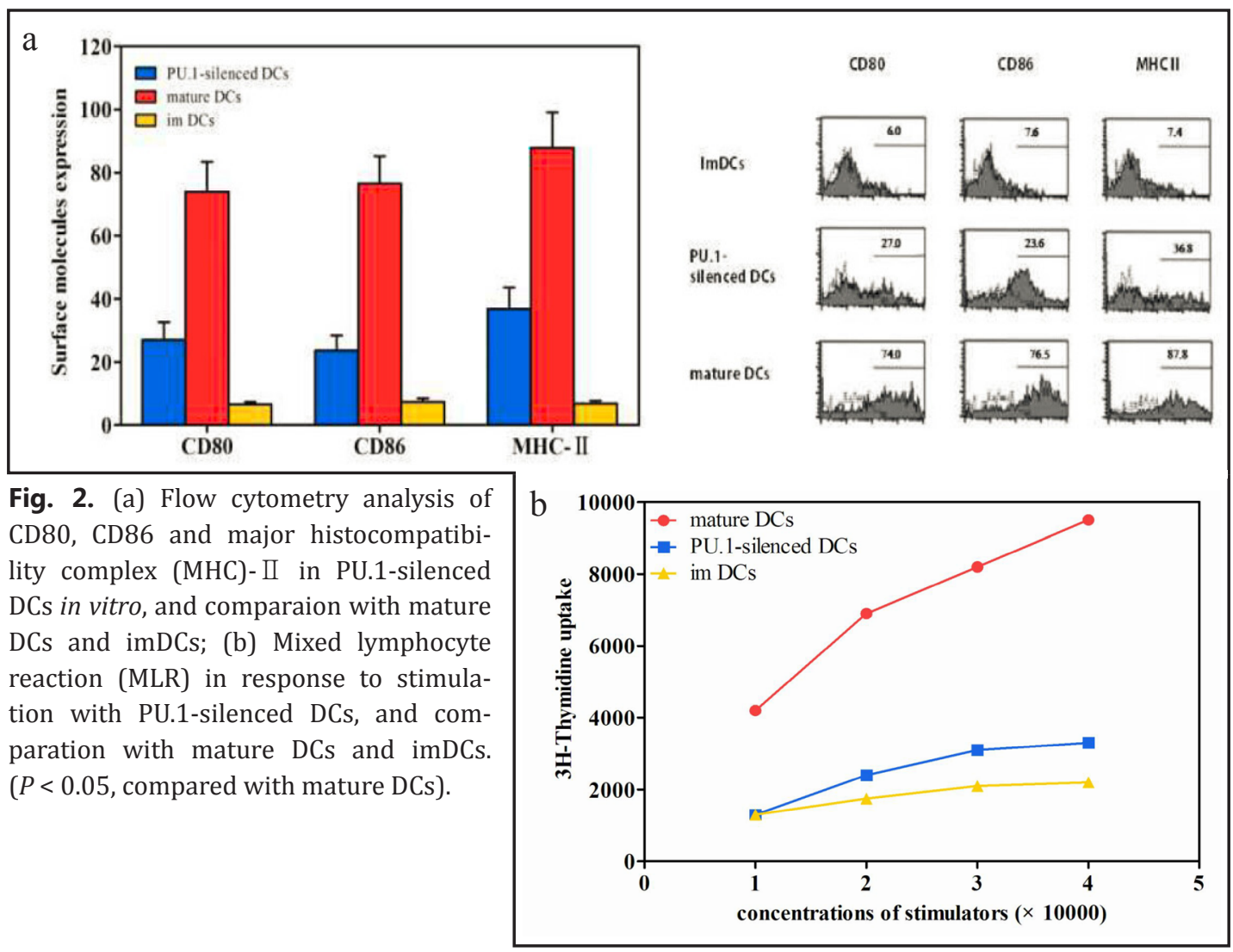

Fig. 3. Real-time PCR analysis for sex-determining region of Y chromosome (SRY) in tissues (blood, liver, spleen and intestine) of female Lewis recipient on day 30. Data were expressed and compared in different groups as the Mean \pm SD $(* p<0.05$, compared with control group; \# $\mathrm{p}<0.05$, compared with BM group; $n=6$ ).

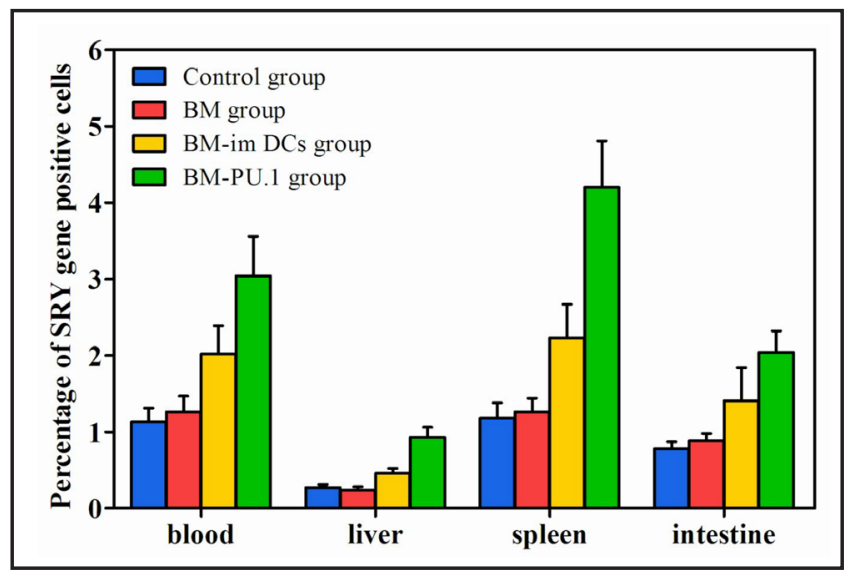

Histopathological examination of grafts

Histopathological examination of the grafts revealed different degrees of lymphocyte infiltration and villous edema at different time points. Evaluation of the histological grade of injuries demonstrated significantly lower scores in the BM-PU.1 group than in the BM group at days 14,21 and $30(0.5 \pm 0.2$ vs $2.7 \pm 0.3, P<0.05 ; 0.7 \pm 0.3$ vs $2.8 \pm 0.3, P<0.05 ; 0.8 \pm 0.3$ vs $3.1 \pm 0.3, P<0.05$, respectively) (Fig. 4 ).

Changes in cytokine expression

ELISA was used to determine the levels of serum IL-2 and IL-10 after intestinal transplantation. The levels of IL-2 increased significantly and peaked on day 14 in the control, BM-imDCs and BM-PU.1 groups. However, in the BM group, IL-2 levels exhibited a decreasing trend after day 7 . All of the curves returned to almost the same level at day 30 . The extent of the increase in IL-2 was reduced in the BM-imDCs and BM-PU.1 groups compared with 


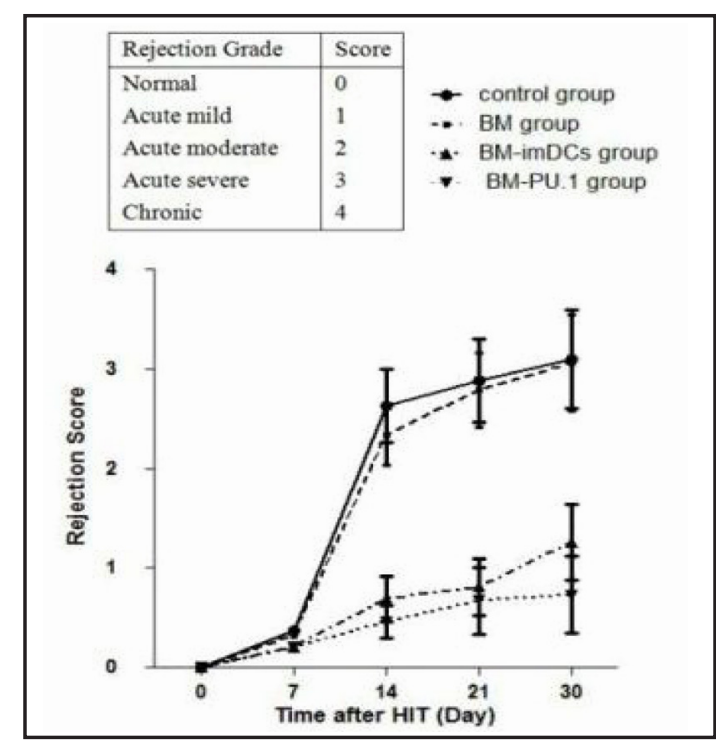

Fig. 4. Histological changes in intestinal grafts after HIT in Lewis rats. The evaluation of the histological grade of grafts was based on the score system (Criterion: normal $=0$; mild, moderate and severe rejection $=1,2$, and 3, respectively; chronic rejection $=4$ ). Data were expressed as the Mean \pm SD.

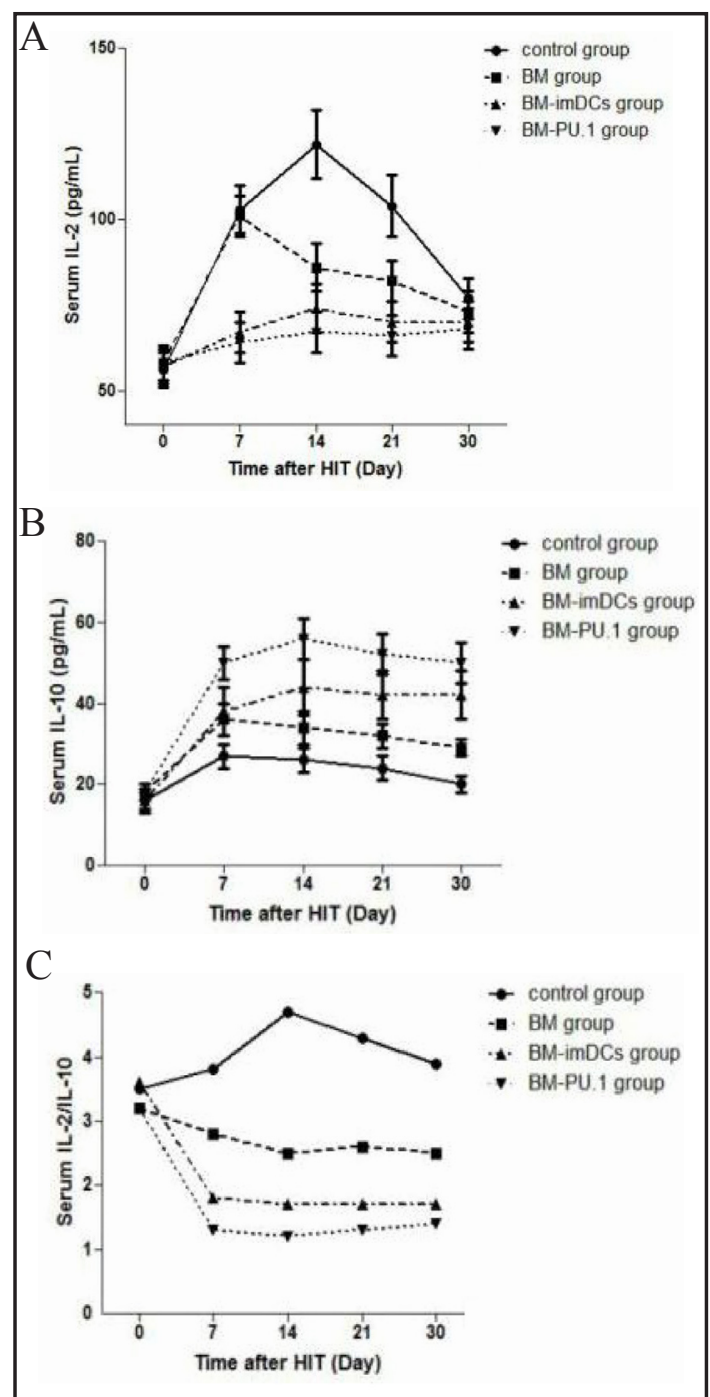

Fig. 5. Trends of serum IL-2, IL-10 and IL-2/IL-10 ratio after HIT by ELISA. Data were expressed as the Mean \pm SD.

the BM group $(P<0.05)$. The IL-2 level in the BM-PU.1 group was slightly lower than that in the BM-imDCs group on days 21 and 30 after HIT $(63.87 \pm 3.20 \mathrm{pg} / \mathrm{ml}$ vs $81.62 \pm 3.47 \mathrm{pg} /$ $\mathrm{ml}, P<0.05 ; 67.22 \pm 2.20 \mathrm{pg} / \mathrm{ml}$ vs $72.06 \pm 3.40 \mathrm{pg} / \mathrm{ml}$, BM-PU.1 vs BM on day 21 and 30 , respectively) (Fig. 5a). Conversely, the IL-10 levels increased after HIT in all groups (Fig. $5 b)$. The IL-10 levels in the control group and BM group peaked on day 7 and then gradually decreased. However, in the BM-imDCs and BM-PU.1 groups, peak levels were observed at day 14 and remained high until day 30. The duration and amplitude of the increase in IL-10 was larger in the BM-PU.1 group than in the other groups $(53.07 \pm 0.94 \mathrm{pg} / \mathrm{ml}$ vs $34.05 \pm$ $0.88 \mathrm{pg} / \mathrm{ml}, P<0.05 ; 50.25 \pm 0.85 \mathrm{pg} / \mathrm{ml}$ vs $32.53 \pm 0.93 \mathrm{pg} / \mathrm{ml}, P<0.05$. BM-PU.1 vs BM on day 21 and 30, respectively). The level of IL-10 in the BM-imDCs group was lower on days 21 and 30 than that in the BM-PU.1 group.

To determine the Th1/Th2 balance, the IL-2/IL-10 ratios were calculated using the data presented in Fig. 5a and Fig. 5b (Fig. 5c). The IL-2/IL-10 ratio in the control group increased and peaked 14 days after HIT. The IL-2/IL-10 ratio decreased sharply in the BM-PU.1 and BM-imDCs groups on day 7 and then remained at a relatively stable level. The IL-2/IL-10 ratio decreased slightly in the BM group and remained at a higher level after day 14 . Fourteen 


\section{Cellular Physiology Cell Physiol Biochem 2016;38:220-228

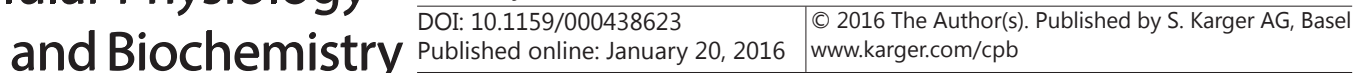 \\ Xu et al.: PU.1-Silenced DCs Synergized to Alleviate Rejection}

days after HIT, the IL2/IL-10 ratios in the control, BM, BM-imDCs and BM-PU.1 groups were $4.7 \pm 0.2,2.6 \pm 0.3,1.8 \pm 0.2$ and $1.3 \pm 0.1$, respectively $(P<0.05)$.

\section{Discussion}

Intestinal transplantation is almost the only life-saving procedure in patients with endstage intestinal disease who fails on TPN and without other available medical or surgical treatment options. However, it is associated with increased morbidity and mortality, which acute and chronic rejection remains a major cause of both early graft loss and unsatisfied long term recipient survival. In recent years, effective immunosuppressants are provided to induce general immunosuppression during the peri-operative period, but they also direct toxicity and some serious side effects yet. How to inducing donor specific immune tolerance and getting a satisfactory graft condition remains a challenge for all transplantation.

Mixed chimerism has been shown to be an attractive method for inducing tolerance in major organ transplantation without the need for lifelong immunosuppression [24, 25]. However, the establishment of long-term and stable chimerism without myeloablative treatments remains a major challenge. In previous studies investigating intestinal transplantation in mice, imDCs were shown to be an alternative to myeloablative conditioning. They established long-term ( $>100$ days) bone marrow chimeras in mice [6] and increased the induction of CD4+CD25+ FoxP3+ regulatory T cells, an indicator and long-term marker of tolerance [26].

We designed an innovative strategy of inducing mixed chimerism after intestinal transplantation in rats. Donor-derived bone marrow cells were transfused through the PV to induce mixed chimerism, while PU.1-silenced DCs were administered 2 days before surgery to facilitate the process. Our results showed that chimerism was successfully established; it was stable and without notable side effects. Even on day 30, bone marrow cells from the donors were observed in the blood, liver and spleen of the recipients and in the small intestine of the recipient adjacent to the grafted donor small intestine. We believe that this strategy has the potential to be an effective method for inducing immune tolerance and reducing toxicity due to myeloablative or cytoreductive recipient conditioning [27]. Histopathological analysis revealed that the BM-PU.1 treatment markedly attenuated mucous atrophy and submucous fibroplasias, especially after day 14. Recipients that did not exhibit long-term stable chimeras and recipients with no chimeras rapidly rejected the allografts, demonstrating the importance of chimerism in the establishment of tolerance.

The Th1/Th2 balance plays an important role in transplantation immunology, and the representative cytokines IL-2 and IL-10 play fundamental roles in regulating this balance. Differentiated Th1 cells excrete IL- 2 and IFN- $\gamma$, which promote the maturation of cytotoxic $\mathrm{T}$ lymphocytes and correlate highly with the severity of transplant rejection and failure. Th2 cells secrete IL-10 and IL-4, which are anti-inflammatory cytokines. IL-10 can downregulate the synthesis of a broad range of inflammatory cytokines and inhibit allogeneic $\mathrm{T}$ cell proliferation by blocking the synthesis of IL-12 in DCs. The production of high levels of endogenous IL-10 has been associated with the function of regulatory T cells and the induction of transplantation tolerance to allogeneic antigens [28]. IL-4 has previously been shown to play a critical role in the establishment of mixed chimerism in irradiation-treated mice. Skewing the immune response towards a Th2 cytokine profile may be one mechanism for inducing immune tolerance. In this study, when severe acute rejection was observed on day 7, high IL-2, low IL-10 and a high IL-2/IL-10 ratio were observed in the control group. This ratio was significantly converted in the BM-PU.1 group, and the values were maintained at a lower level from day 7 to day 30. These results indicate that when used in HIT, PU.1silenced DCs followed by bone marrow transfusion can induce T-cell anergy, produce stable mixed chimerism, and lead to Th2 polarization, converting the IL-2/IL-10 ratio. These findings are consistent with previous reports showing that induction of allogeneic mixed 


\section{Cellular Physiology Cell Physiol Biochem 2016;38:220-228 \begin{tabular}{l|l|l}
\hline DOI: 10.1159/000438623 2016 & $\begin{array}{l}\text { C) 2016 The Author(s). Published by S. Karger AG, Basel } \\
\text { www.karger.com/cpb }\end{array}$
\end{tabular} \\ Xu et al.: PU.1-Silenced DCs Synergized to Alleviate Rejection}

chimerism using imDCs and bone marrow transplantation leads to prolonged tolerance in cardiac and skin transplantation [6].

To our knowledge, it is the first report of the establishment of long-lasting mixed chimeras in rats through pre-conditioning with PU.1-silenced DCs and donor derived bone marrow transfusion. This conditioning regime induces more stable mixed chimerism, promote a Th2 shift in Th1/Th2 balance and facilitate the induction of immune tolerance. It has a potential to allow the long-term survival of grafts without additional need for immunosuppression or myeloablative therapies. Based on these findings, our study may suggest to being among potential clinical solutions to prevent rejection and achieve immunological tolerance prior to organ transplantation. However, further studies are still planned to investigate whether immunosuppression can halt allograft rejection after chimera loss.

\section{Acknowledgements}

We thank He Qin, Wang Chenyang and Xu Yuqin for technical support in the laboratery of Jinling Hospital.

The work was supported by grants from "Natural Science Foundation of Jiangsu Province"(No. BK2008237), "Nanjing Science and Technology Development Plan"(No. 201104027) and "The Scientific Research Foundation of Graduate School of Nanjing University" (No. 2014CL02).

\section{Disclosure Statement}

The authors do not have any conflict of interest, personal or organizational, financial or familial, real or apparent, in participating in this procurement.

\section{References}

1 Fishbein TM: Intestinal transplantation. N Engl J Med 2009;361:998-1008.

2 Ruiz P, Kato T, Tzakis A: Current status of transplantation of the small intestine. Transplantation 2007;83:16.

3 Pondrom S: The AJT report. Survival rates increase in bowel transplantation: seldom-done procedure comes of age. Am J Transplant 2010;10:438-440.

4 Abu-Elmagd KM, Costa G, Bond GJ, Wu T, Murase N, Zeevi A, Simmons R, Soltys K, Sindhi R, Stein W, Demetris A, Mazariegos G: Evolution of the immunosuppressive strategies for the intestinal and multivisceral recipients with special reference to allograft immunity and achievement of partial tolerance. Transpl Int 2009;22:96-109.

5 Abu-Elmagd KM, Costa G, Bond GJ, Soltys K, Sindhi R, Wu T, Koritsky DA, Schuster B, Martin L, Cruz RJ, Murase N, Zeevi A, Irish W, Ayyash MO, Matarese L, Humar A, Mazariegos G: Five hundred intestinal and multivisceral transplantations at a single center: major advances with new challenges. Ann Surg 2009;250:567-581.

6 Yu P, Xiong S, He Q, Chu Y, Lu C, Ramlogan CA, Steel JC: Induction of allogeneic mixed chimerism by immature dendritic cells and bone marrow transplantation leads to prolonged tolerance to major histocompatibility complex disparate allografts. Immunology 2009;127:500-511.

$7 \quad$ Pilat N, Wekerle T: Transplantation tolerance through mixed chimerism. Nat Rev Nephrol 2010;6:594-605.

8 Fudaba Y, Spitzer TR, Shaffer J, Kawai T, Fehr T, Delmonico F, Preffer F, Tolkoff-Rubin N, Dey BR, Saidman SL, Kraus A, Bonnefoix T, McAfee S, Power K, Kattleman K, Colvin RB, Sachs DH, Cosimi AB, Sykes M: Myeloma responses and tolerance following combined kidney and nonmyeloablative marrow transplantation: in vivo and in vitro analyses. Am J Transplant 2006;6:2121-2133. 


\section{Cellular Physiology Cell Physiol Biochem 2016;38:220-228 \begin{tabular}{cl|l} 
DOI: 10.1159/000438623 2016 & $\begin{array}{l}\text { O 2016 The Author(s). Published by S. Karger AG, Basel } \\
\text { www.karger.com/cpb }\end{array}$
\end{tabular} \\ Xu et al.: PU.1-Silenced DCs Synergized to Alleviate Rejection}

9 Kawai T, Cosimi AB, Spitzer TR, Tolkoff-Rubin N, Suthanthiran M, Saidman SL, Shaffer J, Preffer FI, Ding R, Sharma V, Fishman JA, Dey B, Ko DS, Hertl M, Goes NB, Wong W, Williams WW, Jr., Colvin RB, Sykes M, Sachs DH: HLA-mismatched renal transplantation without maintenance immunosuppression. N Engl J Med 2008;358:353-361.

10 Park HJ, Im SA, Chun HJ, Park SH, O JH, Lee KY: Changes in CT appearance of intrathoracic gossypiboma over 10 years. Br J Radiol 2008;81:e61-63.

11 Andreacci JL, Dixon CB, Ledezma C, Goss FL: Effect of intermittent sub-maximal exercise on percent body fat using leg-to-leg bioelectrical impedance analysis in children. J Sports Sci Med 2006;5:424-430.

12 Wu L, Liu YJ: Development of dendritic-cell lineages. Immunity 2007;26:741-750.

13 Kanada S, Nishiyama C, Nakano N, Suzuki R, Maeda K, Hara M, Kitamura N, Ogawa H, Okumura K: Critical role of transcription factor PU.1 in the expression of CD80 and CD86 on dendritic cells. Blood 2011;117:2211-2222.

14 Kitamura N, Yokoyama H, Yashiro T, Nakano N, Nishiyama M, Kanada S, Fukai T, Hara M, Ikeda S, Ogawa H, Okumura K, Nishiyama C: Role of PU.1 in MHC class II expression through transcriptional regulation of class II transactivator pI in dendritic cells. J Allergy Clin Immunol 2012;129:814-824.

15 Yashiro T, Kubo M, Ogawa H, Okumura K, Nishiyama C: PU.1 suppresses Th2 cytokine expression via silencing of GATA3 transcription in dendritic cells. Plos One 2015;10:e0137699.

16 Fukai T, Nishiyama C, Kanada S, Nakano N, Hara M, Tokura T, Ikeda S, Ogawa H, Okumura K: Involvement of PU.1 in the transcriptional regulation of TNF-alpha. Biochem Biophys Res Commun 2009;388:102-106.

17 Suzuki M, Yamada T, Kihara-Negishi F, Sakurai T, Hara E, Tenen DG, Hozumi N, Oikawa T: Site-specific DNA methylation by a complex of PU.1 and Dnmt3a/b. Oncogene 2006;25:2477-2488.

18 Carotta S, Dakic A, D'Amico A, Pang SH, Greig KT, Nutt SL, Wu L: The transcription factor PU.1 controls dendritic cell development and Flt3 cytokine receptor expression in a dose-dependent manner. Immunity 2010;32:628-641.

19 Lutz MB, Suri RM, Niimi M, Ogilvie AL, Kukutsch NA, Rossner S, Schuler G, Austyn JM: Immature dendritic cells generated with low doses of GM-CSF in the absence of IL-4 are maturation resistant and prolong allograft survival in vivo. Eur J Immunol 2000;30:1813-1822.

20 Xu XW, Ding BW, Zhu CR, Ji W, Li JS: PU.1-silenced dendritic cells prolong allograft survival in rats receiving intestinal transplantation. World J Gastroenterol 2013;19:7766-7771.

21 Szabo A, Vollmar B, Boros M, Menger MD: Gender differences in ischemia-reperfusion-induced microcirculatory and epithelial dysfunctions in the small intestine. Life Sci 2006;78:3058-3065.

22 Kiyomoto T, Toyokawa H, Nakao A, Kaizu T, Demetris AJ, Starzl TE, Murase N: The difficulty of eliminating donor leukocyte microchimerism in rat recipients bearing established organ allografts. Transplantation 2006;81:438-444.

23 Hu A, Li Q Shi H, Tai Q, Wu L, Xiong J, Fu B, He X: Donor-derived bone marrow transfusion produces mixed chimerism and promotes a Th2 shift in Th1/Th2 balance in rat heterotopic small bowel transplantation. Dig Liver Dis 2012;44:988-994.

24 Field EH, Rouse T: Requirements for developing mixed-chimerism in nonmyeloablative total-lymphoid irradiated mice: role of IL-4 and immunoredirection. Transplantation 2002;74:1021-1029.

25 Pilat N, Hock K, Wekerle T: Mixed chimerism through donor bone marrow transplantation: a tolerogenic cell therapy for application in organ transplantation. Curr Opin Organ Transplant 2012;17:63-70.

26 Cobbold SP: Regulatory T cells and transplantation tolerance. J Nephrol 2008;21:485-496.

27 Yamada K, Scalea J: Current progress in xenogeneic tolerance. Curr Opin Organ Transplant 2012;17:168173.

28 Cottrez F, Hurst SD, Coffman RL, Groux H: T regulatory cells 1 inhibit a Th2-specific response in vivo. J Immunol 2000;165:4848-4853. 